\title{
Bacterial Paediatric Meningitis Laboratory Diagnosis
}

Gudza-Mugabe $\mathbf{M}^{1 *}$, Robertson $\mathbf{V}^{\mathbf{2}}$, Mapingure $\mathbf{M P}^{3}$, Mtapuri-Zinyowera $\mathbf{S}^{\mathbf{1}}$ and Mavenyengwa $\mathbf{R T}^{\mathbf{2}}$

${ }^{1}$ National Microbiology Reference Laboratory, Harare Central Hospital , Southerton, Harare, Zimbabwe

${ }^{2}$ Department of Medical Microbiology, University of Zimbabwe College of Health Sciences, Avondale, Harare, Zimbabwe

${ }^{3}$ SACORE, Research Support Centre, University of Zimbabwe College of Health Sciences, Zimbabwe

\begin{abstract}
Introduction: Bacterial meningitis is one of the top ten causes of death amongst children under 5 years in Zimbabwe. Optimizing the identification of the etiologic agents of bacterial meningitis leads to better management of patients. The objective of this study was to compare the effectiveness of latex agglutination (LA), culture and Polymerase Chain Reaction (PCR) as diagnostic methods in the detection of Neisseria meningitidis, Streptococcus pneumoniae, Streptococcus agalactiae and Haemophilus influenzae in paediatric cerebral spinal fluids (CSF) specimens at Harare Children's Hospital $(\mathrm{HCH})$.
\end{abstract}

Methodology: Specimens from 162 clinically suspected paediatric cases of bacterial meningitis were processed by cell count, Gram stain, culture, latex agglutination and PCR

Results: Forty-nine (30.2\%) suspected cases were positive for at least one of the four bacterial organisms. The latex agglutination test was positive in $33 / 49(67.3 \%)$ cases, PCR was positive in $37 / 49(75.5 \%)$ and culture was positive for $17 / 49(34.7 \%)$ cases. Streptococcus pneumoniae was the predominant pathogen detected in 29 of the 49 positive cases $(59.2 \%)$ followed by S. agalactiae detected in $11 / 49(22.4 \%)$ cases. Haemophilus influenzae was detected in $7 / 49(14.3 \%)$ cases while N. meningitidis accounted for $2 / 49(4.1 \%)$ positive cases. Thirty-three $(20.4 \%)$ CSF samples tested positive with the latex agglutination test. This increased the number of organisms above that detected by culture by $16 / 49$ (32.6\%). Polymerase chain reaction detected 37 CSF samples increasing the number of organisms detected by culture by $20 / 49(40.8 \%)$.

Conclusion: Bacterial meningitis mainly caused by Streptococcus pneumoniae is prevalent among children in Zimbabwe and coupling of culture and non-culture methods can improve detection of the disease.

Keywords: Paediatric; Meningitis; culture; Latex agglutination; PCR

\section{Introduction}

Bacterial meningitis requires prompt diagnosis and treatment to reduce the development of neurological sequelae and deaths [1]. Meningitis causing bacteria such as Neisseria meningitidis, Streptococcus pneumoniae, and Haemophilus influenzae type $\mathrm{b}$ (Hib) are among the main causative organisms of bacterial meningitis globally, accounting for $90 \%$ of reported cases in infants and children aged $>60$ days [2]. Streptococcus agalactiae is also an important causative organism of maternal and neonatal morbidity and mortality in many parts of the world and contributes to these cases of meningitis [3].

Bacterial meningitis accounts for $2 \%$ of child death worldwide but the burden of meningococcal meningitis is highest in the African meningitis belt covering the West, Central and East African countries. World Health Organisation (WHO) 2002-2008 surveillance data shows a high burden of meningitis in the Southern African countries even when a large number of infants in the rural areas who are not able to access health facilities are not represented in the data [4].

The infection kills about 1000 people a day and infects about a million people per year on the continue [5]. Neisseria meningitidis is responsible for large epidemics causing thousands of deaths from the 700,000 cases of meningitis reported in these countries [6,7]. Haemophilus influenzae type $\mathrm{b}$ disease causes 3 million cases of meningitis and severe pneumonia and approximately 386,000 deaths worldwide per year in children aged $<5$ years [7]. Pneumococcal disease is a leading cause of childhood morbidity and mortality globally, causing an estimated 0.7-1.0 million deaths annually among children aged $<5$ years [6]. Streptococcus agalactiae is responsible for an estimated 900 deaths per 100000 live births [8].
The laboratory plays an important role in the detection and confirmation of meningitis cases. Examination of the cerebrospinal fluid (CSF) is frequently used to provide immediate confirmation of acute bacterial meningitis [9].

Use of effective laboratory methods to improve detection of pathogens in patients with suspected meningitis is important. Traditional methods in routine laboratory diagnosis in developing African countries have led to limited detection of bacterial meningitis. Latex agglutination and PCR methods can increase sensitivity and improve diagnosis as additional diagnostic tools especially for culture negative CSF specimens [10].

The potential S. pneumoniae detection by PCR in bacterial meningitis has been demonstrated to be 5-10 times higher than by culture [11]. The sensitivity of PCR based tests is reduced in CSF samples after pre-treatment with antibiotics [12] in PCR based diagnosis in patients with meningococcal disease. This current study focuses on comparison of different laboratory diagnostic techniques for

*Corresponding author: Gudza MM, National Microbiology Reference Laboratory, Harare Central Hospital, 2nd Floor, Laboratory Complex, P.O. Box ST 749, Southerton, Harare, Zimbabwe, Tel: +263773214886; E- mail: gudzam@gmail.com

Received February 10, 2015; Accepted April 21, 2015; Published April 23, 2015

Citation: Gudza-Mugabe M, Robertson V, Mapingure MP, Mtapuri-Zinyowera S, Mavenyengwa RT (2015) Prevalence of Salmonellosis among Food Handlers and the Health Implications on the Food Consumers in Lagos State, Nigeria. J Med Microb Diagn 4: 183. doi:10.4172/21610703.1000183

Copyright: $\odot 2015$ Gudza-Mugabe M, et al. This is an open-access article distributed under the terms of the Creative Commons Attribution License, which permits unrestricted use, distribution, and reproduction in any medium, provided the origina author and source are credited. 
Citation: Gudza-Mugabe M, Robertson V, Mapingure MP, Mtapuri-Zinyowera S, Mavenyengwa RT (2015) Prevalence of Salmonellosis among Food Handlers and the Health Implications on the Food Consumers in Lagos State, Nigeria. J Med Microb Diagn 4: 183. doi:10.4172/21610703.1000183

identification of bacteria causing meningitis in a low income setting where there is high empirical use of antibiotics.

\section{Methodology}

\section{Study design}

This was an analytical cross-sectional study conducted at Harare Central Hospital $(\mathrm{HCH})$ paediatric unit from January 2012 to August 2012. The selection criteria included children aged 60 months or less admitted to Harare Central Paediatric Hospital with suspected meningitis. Convenience sampling of CSF specimens collected by the clinicians both during the day and at night was done at the laboratory excluding specimens that were bloody or of insufficient amounts.

The project samples were a part of an on-going surveillance of paediatric bacterial meningitis survey being done by the Ministry of Health and Child Care supported by the World Health Organisation.

\section{Sample size}

The simple formula for difference in proportions was used by setting culture at $0.5758=\mathrm{p} \pi 1$; latex agglutination at $0.405=\mathrm{p} \pi 2$ and PCR at $1=\mathrm{p} \pi 3$.This was done to give a power of $80 \%$ with $Z \beta=0.84$, at 0.05 significance level i.e. $Z \alpha / 2=1.96$ was used:

$$
n=\frac{2(0.9808)(1-0.9808)(0.84+1.96)^{2}}{(0.5758-0.405)^{2}}
$$

Hence sample size $(\mathrm{n})$ was calculated as: [13].

This gave a sample size of 129 based on a similar comparison study

\section{Sample preparation and processing}

The CSF samples which met the selection criteria were received and processed within 1 hour of reception in the laboratory. The CSF specimens were processed using the Gram stain, cell count, culture and Latex Agglutination (LA). Macroscopic examination to determine the appearance was done.

\section{Cell count}

A cell count to measure the number of red and white blood cells was done on the CSF specimen before centrifugation using a Fuchs Rosenthal Counting Chamber [14].

\section{Culture}

The CSF specimens were centrifuged at $3000 \mathrm{rpm}$ for 5 minutes and the deposit used for culture and to prepare smears for staining. The sediment was cultured and further processed using standard bacteriological techniques. Briefly blood agar and chocolate agar supplemented with $5 \%$ sheep blood were prepared using tryptone soy agar (Mast diagnostics, U.K.) and incubated in $5 \% \mathrm{CO}_{2}$ at $37^{\circ} \mathrm{C}$ for 24-48 hours. All laboratory procedures were quality controlled using American Type Culture Collection (ATCC) controls, S. pneumoniae ATCC 49619, E. coli ATCC 25922 and H. influenzae ATCC49247. Identification of the isolates was done using standard laboratory tests [14]. The isolates were stored at $-80^{\circ} \mathrm{C}$ in skimmed milk for further identification and referral purposes at the National Microbiology Reference Laboratory (NMRL).

\section{Latex agglutination test}

A latex agglutination test was performed to detect bacterial antigens of N. meningitidis, S. pneumoniae, S. agalactiae and H. influenzae using a Pastorex meningitis kit (Bio-rad, France) according to manufacturer`s instructions.

\section{PCR}

Residual CSF specimens were stored in cryovials at $-20^{\circ} \mathrm{C}$ until the time for shipment to the National Institute for Communicable Diseases (NICD) a referral laboratory in South Africa for processing by multiplex real time PCR using primers shown in Table 1, based on Carvalho et al. [15]. Stored isolates were sub-cultured and put on skimmed milk media and sent to NICD at the end of each month for further identification and serotyping. The remaining isolates were kept for referral purposes at NMRL.

\section{Ethical considerations}

Project approval was obtained from the $\mathrm{HCH}$ Ethical committee, Joint Research Ethics committee (JREC) and the Medical Research Council of Zimbabwe (MRCZ).Written consent to perform lumbar puncture was requested from parents by clinicians. The results obtained were released to the relevant clinician.

\section{Data analysis}

Data analysis was conducted using STATA Version 10.0. Proportions were used to describe organism detection levels. A test of proportions was used to compare differences in the detection levels for various organisms by the three methods. Sensitivities and specificities of methods were not calculated as unknown samples were being used for the detection of pathogens.

\section{Results}

A total of 246 paediatric CSF specimens which met the inclusion criteria were received in the laboratory of which 84 were of insufficient volume for performance of all the three tests. The analysis of results was therefore based on $162 \mathrm{CSF}$ samples with definite positive and negative results from the 3 methods. A total of 78 (48.1\%) samples

\begin{tabular}{|c|c|c|c|c|}
\hline Species & Gene Target & Primer name & Nucleotide sequence $5^{\prime}-3^{\prime}$ & Working concentration $(\mu \mathrm{M})$ \\
\hline N.meningitidis & ctrA & $\begin{array}{l}\text { F753 } \\
\text { R846 } \\
\text { Pb820i }\end{array}$ & $\begin{array}{l}\text { TGTGTTCCGCTATACGCCATT } \\
\text { GCCATATTCACACGATATACCAACCTTGAGCAA"T"CCATTT } \\
\text { ATCCTGACGTTCT } \\
\text { 5`FAM;3`SpC6;"T"BHQ1 }\end{array}$ & $\begin{array}{l}7.5 \\
22.5 \\
2.5\end{array}$ \\
\hline H. influenzae & Hpd & $\begin{array}{l}\text { HPDF729 } \\
\text { HPDR819 } \\
\text { PBR762i }\end{array}$ & $\begin{array}{l}\text { AGATTGGAAAGAAACACAAGAAAAAGA } \\
\text { CACCATCGGCATATTTAACCACT } \\
\text { AAACATCCAATCG"T"AATTATAGTTTACCCAATAACCC } \\
\text { 5`HEX;3`SpC6;BHQ1 }\end{array}$ & $\begin{array}{l}7.5 \\
2.5 \\
5\end{array}$ \\
\hline S. pneumoniae & lytA & $\begin{array}{l}\text { F373 } \\
\text { R424 } \\
\text { Pb400i }\end{array}$ & $\begin{array}{l}\text { ACGCAATCTAGCAGATGAAGCA } \\
\text { TCGTGCGTTTTAATTCCAGCT } \\
\text { TGCCGAAAACGC"T"TGATACAGGGAG } \\
5{ }^{\circ} \text { Cy5;3`SpC6;"T"BHQ2 }\end{array}$ & $\begin{array}{l}5 \\
5 \\
5\end{array}$ \\
\hline
\end{tabular}

Table 1: Primers and probes used for Real time PCR. 
Citation: Gudza-Mugabe M, Robertson V, Mapingure MP, Mtapuri-Zinyowera S, Mavenyengwa RT (2015) Prevalence of Salmonellosis among Food Handlers and the Health Implications on the Food Consumers in Lagos State, Nigeria. J Med Microb Diagn 4: 183. doi:10.4172/21610703.1000183

Page 3 of 6

were from male participants, 76 (46.9\%) were females while $8(4.9 \%)$ samples had no data on the sex of the participants. Antibiotic use before lumbar puncture was reported in $27(16.0 \%)$ participants though no specific antibiotics were cited, while 39 (24.1\%) had lumbar puncture performed before administration of antibiotics (Table 2). Bacterial meningitis was confirmed by culture, LA and PCR in 53 cases of which $48(90.6 \%)$ cases were confirmed in children $\leq 12$ months of age while 3 (6\%) were confirmed in children between 13-60 months. Two cases (4\%) were confirmed in the children where the age was not given.

\section{Pathogens identified}

A summary of the results from the 246 CSF specimens collected is shown in a representation of the laboratory findings flow chart in Figure 1. Out of the $53(32.7 \%)$ meningitis cases, the most common pathogen identified by at least two of the methods used was S. pneumoniae which was detected in 29 (54.7\%) CSF specimens followed by S. agalactiae which was detected in 11 (20.8\%). Fewer cases of $H$. influenzae $7(13.2 \%)$ were detected while the least common organism detected was $N$. meningitides $2(3.8 \%)$ and $4(7.5 \%)$ other types of organisms were identified. Additional organisms identified were $3 \mathrm{Gram}$ negative lactose fermenting coliforms, $(2 \mathrm{E}$. coli, and one that could not be identified to species level) and one coagulase negative staphylococcus.

\section{Distribution of identified organisms by age}

The four pathogens S. pneumoniae, S. agalactiae, H. influenzae and $N$. meningitides were identified by PCR in the 0-2 months and 3-12

\begin{tabular}{|l|c|c|c|}
\hline \multirow{2}{*}{ Characteristics } & \multicolumn{3}{|c|}{ Meningitis cases } \\
\hline Sex & Confirmed & Negative & Total \\
\hline Female & $\mathbf{n = 4 9 ( \% )}$ & $\mathbf{n = 1 1 3}(\%)$ & $\mathbf{n = 1 6 2 ( \% )}$ \\
\hline Male & $26(53.1)$ & $50(44.2)$ & $76(46.9)$ \\
\hline Not given & $22(44.9)$ & $56(49.6)$ & $78(48.1)$ \\
\hline Age (months) & $1(2.0)$ & $7(6.2)$ & $8(4.9)$ \\
\hline $0-2$ & $23(46.9)$ & $78(69.0)$ & $101(62.3)$ \\
\hline \multicolumn{1}{|c|}{ 12-Mar } & $21(42.9)$ & $23(20.4)$ & $44(27.2)$ \\
\hline $13-24$ & $2(4.1)$ & $5(4.4)$ & $7(4.3)$ \\
\hline $25-60$ & $1(2.0)$ & $1(0.9)$ & $2(1.2)$ \\
\hline Not given & $2(4.1)$ & $6(5.3)$ & $8(4.9)$ \\
\hline Prior antibiotic use & & & $27(16.0)$ \\
\hline Yes & $7(14.3)$ & $20(17.7)$ & $39(24.1)$ \\
\hline No & $14(28.6)$ & $25(22.1)$ & $96(59.3)$ \\
\hline Not stated & $28(57.1)$ & $68(60.2)$ & \\
\hline
\end{tabular}

Table 2: Characteristics of study population.

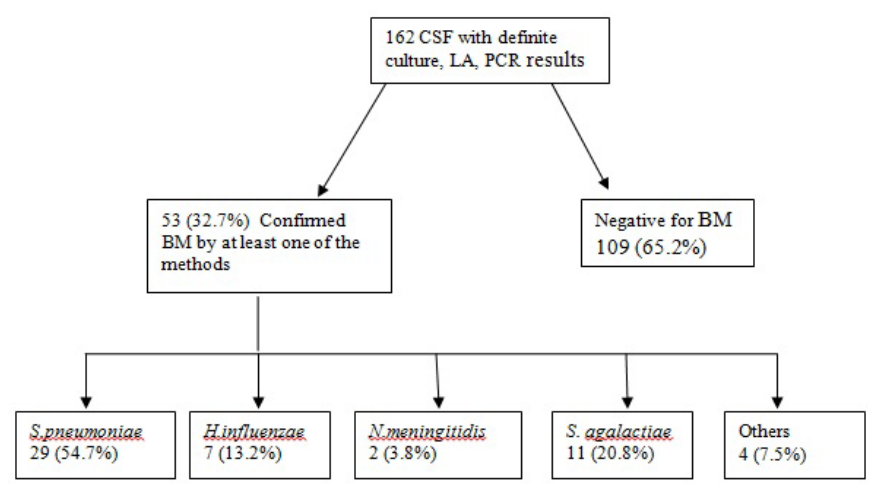

Figure 1: Summary of proportions of identified organisms.

\begin{tabular}{|l|c|c|c|c|c|}
\hline $\begin{array}{l}\text { Age Group } \\
\text { in months }\end{array}$ & \multicolumn{5}{|c|}{ Organism } \\
\hline & N.meningitidis & S.pneumoniae & S. agalactiae ** & H. influenzae & Other \\
\hline $0-2(n=101)$ & 1 & 12 & 7 & 2 & 3 \\
$3-12(n=44)$ & 1 & 14 & 3 & 4 & 1 \\
$13-24(n=7)$ & 0 & 0 & 1 & 1 & 0 \\
$25-60(n=2)$ & 0 & 1 & 0 & 0 & 0 \\
Age not & 0 & 2 & 0 & 0 & 0 \\
given $(n=8)$ & 2 & 29 & 11 & 7 & 4 \\
\hline Total N=162 & 2 & & & \\
\hline ** As detected by Latex agglutination. & & & & \\
\hline
\end{tabular}

Table 3: Distribution of organisms in patients based on age

\begin{tabular}{|c|c|c|c|}
\hline \multirow[t]{2}{*}{ Characteristics } & \multicolumn{3}{|c|}{ Meningitis cases } \\
\hline & $\begin{array}{l}\text { Confirmed } \mathrm{n}=49 \\
(\%)\end{array}$ & $\begin{array}{l}\text { Negative for meningitis } \\
n=113(\%)\end{array}$ & $\begin{array}{l}\text { Total } n=162 \\
(\%)\end{array}$ \\
\hline $\begin{array}{l}\text { CSF appearance } \\
\text { Clear } \\
\text { Xanthochromic } \\
\text { Turbid/cloudy } \\
\text { Blood stained }\end{array}$ & $\begin{array}{c}24(48.9) \\
6(12.2) \\
9(18.3) \\
10(20.4)\end{array}$ & $\begin{array}{c}57(50.4) \\
22(19.4) \\
3(2.6) \\
31(27.4)\end{array}$ & $\begin{array}{c}81(50.0) \\
28(17.2) \\
12(7.4) \\
41(25.3)\end{array}$ \\
\hline $\begin{array}{l}\text { WBC count cell/mm } \\
<5 \\
5-10 \\
11-99 \\
>=100\end{array}$ & $\begin{array}{c}13(26.5) \\
16(32.6) \\
6(12.2) \\
14(28.5)\end{array}$ & $\begin{array}{c}37(32.7) \\
49(43.3) \\
24(21.2) \\
3(2.6)\end{array}$ & $\begin{array}{l}50(30.8) \\
65(40.1) \\
30(18.5) \\
17(10.4)\end{array}$ \\
\hline $\begin{array}{l}\text { Gram staining results } \\
\text { Positive } \\
\text { Negative }\end{array}$ & $\begin{array}{l}22(44.8) \\
27(55.1)\end{array}$ & $\begin{array}{c}6(5.3) \\
107(94.7)\end{array}$ & $\begin{array}{l}28(17.3) \\
134(82.7)\end{array}$ \\
\hline
\end{tabular}

Table 4: Cerebrospinal fluid laboratory findings.

\begin{tabular}{|c|c|c|c|}
\hline \multirow[t]{2}{*}{ Organism } & \multicolumn{3}{|l|}{ Detection method } \\
\hline & Culture $n=162(\%)$ & Latex $n=162(\%)$ & PCR $n=162(\%)$ \\
\hline N. meningitidis & $0 \quad(0.0)$ & $1(0.6)$ & $1(0.6)$ \\
\hline S. pneumoniae & $15 \quad(9.3)$ & $20(12.3)$ & 29 (17.9) \\
\hline S. agalactiae & $1(0.6)$ & $11(7.4)$ & $\mathrm{ND}^{*}$ \\
\hline H. influenzae & $1(0.6)$ & $1(0.6)$ & $7 \quad(4.3)$ \\
\hline Total & $17(10.5)$ & $33 \quad(20.4)$ & $37 \quad(22.9)^{\star *}$ \\
\hline
\end{tabular}

Table 5: Meningitis causing bacteria detected by culture, LA and PCR.

months old groups while $S$. pneumoniae was the only species isolated from children in the group 25-60 months (Table 3). The majority of the cases (26) were due to pneumococcus reported in infants $\leq 2$ and in children between 3-12 months. Of the 11 cases of S. agalactiae, 4 were identified as early onset infection which is evident in the first week of life and the other 6 cases were late onset which is disease detected after the first week to 3 months of life and the single remainder of the cases can be regarded as late, late onset.

There were 50/162 (30.9\%) CSF specimens with $<5$ WBC and $17 / 162(10.5 \%)$ had $\geq 100 / \mathrm{mm}^{3}$ (Table 4 ). The mean of WBC cell count was $59.5 / \mathrm{mm}^{3}$. The Gram stain of the CSF was positive (organisms seen) for $28 / 162(17.3 \%)$ of the children while in $134 / 162(82.7 \%)$ CSF specimens had a negative Gram stain (no organisms were seen).

\section{Comparison of culture, LA and PCR in detecting bacterial causes of meningitis}

Table 5 shows that a total of 17 isolates from CSF specimens of which 14 were positive with Gram stain were detected by culture method. The species identified were S. pneumoniae (15) H. influenzae (1) and S. agalactiae (1). Of the 17 isolates 16 were also positive with LA and PCR. The Latex agglutination test tested positive in 33 out of 49 CSF samples giving a positive rate of $67.3 \%$ increasing the number of organisms above that detected by culture by 16 (32.6\%). This number includes 11 samples that were positive for $S$. agalactiae which were 
Citation: Gudza-Mugabe M, Robertson V, Mapingure MP, Mtapuri-Zinyowera S, Mavenyengwa RT (2015) Prevalence of Salmonellosis among Food Handlers and the Health Implications on the Food Consumers in Lagos State, Nigeria. J Med Microb Diagn 4: 183. doi:10.4172/21610703.1000183

not tested by PCR because of unavailability of primers. However there were 3 samples $N$. meningitidis (1), S. pneumoniae (2) with positive latex results which were negative with both PCR and culture. The PCR method detected 29 S. pneumoniae, 1 N. meningitidis and 7 H.influenzae in 37 samples increasing the number of organisms detected by PCR over culture by 20 (40.8\%). There were 16 samples S. pneumoniae (9), $N$. meningitides (1), and $H$. influenzae (6) with positive PCR results which tested negative with LA and culture.

\section{Comparison of organisms detected by culture, LA and PCR}

The culture method isolated all of the three types of organisms except $N$. meningitidis (Table 5). The highest number of isolates from culture was S. pneumoniae representing $15 / 17$ (88.2\%) of the total isolates while there was one each for $S$. agalactiae and $H$. influenzae. Latex agglutination detected each type of the 3 different organisms. A higher detection rate for $S$. pneumoniae 20/33(60.6\%) than that of $S$. agalactiae 11/33(33.3\%) was found. Only one isolates each of N.meningitidis and $H$. influenzae was detected. Out of the 33 samples in which organisms were detected by latex, 3 (N. meningitidis 1 ; and $S$. pneumoniae 2; were detected by latex agglutination only. Polymerase chain reaction detected all the three species (Table 5). More $S$. pneumoniae and $H$. influenzae were detected by PCR than the other 2 methods. Out of the total of 29 S. pneumoniae detected, 10(34.5\%) were detected by PCR only while $4(13.8 \%)$ were detected by both PCR and LA only. Out of the $7 \mathrm{H}$. influenzae detected 6/7(85.7\%) were detected by PCR only and N.meningitidis was detected in only one specimen by the PCR method. Four specimens identified using LA as S. agalactiae were processed using PCR and 3 different organisms S. pneumoniae (1), $N$. meningitides (1) and $H$. influenza (2), were detected.

\section{Statistical significance between methods of detection}

There were no significant differences in bacterial meningitis detection rates between culture, LA and PCR but there were significant differences in the detection of individual species Detection rates for S. pneumoniae between culture and PCR were significantly different $(\mathrm{p}=0.024)$ as PCR detected more $S$. pneumoniae in more specimens. Detection rates for $H$. influenzae were also significantly $(\mathrm{p}=0.032)$ different between culture and latex or PCR. Polymerase Chain Reaction was better in the detection of $H$. influenzae than culture or LA. Detection rates for $S$. agalactiae between culture and LA were significantly different $(\mathrm{p}=0.002)$ as LA was better in the detection of $S$. agalactiae than culture.

\section{Discussion}

\section{Bacterial causes of meningitis}

The most common cause of meningitis in children $<5$ years admitted to $\mathrm{HCH}$ was found to be S. pneumoniae 29/53(54.7.2\%) and S. agalactiae $11 / 53(20.7 \%)$ followed by $H$. influenzae $7 / 53(13.2 \%)$. Other pathogens N.meningitidis and E. coli were identified in children in the $<1$ year age group but were not common. The majority of the confirmed cases $48 / 53$ (90\%) occurred in infants in the 0-12 months age group. This result is higher than that reported by Roca et al., [16] in neighboring Mozambique where confirmed cases of acute bacterial meningitis cases (67\%) occurred among infants of $<1$ year of age and also the number of cases caused by $N$. meningitidis was much higher. Brouwer et al., [10] suggests that the most common causative organisms of meningitis in neonates are $S$. agalactiae, L. monocytogenes and E. coli. In this study $S$. pneumoniae was the most common cause of meningitis in the neonates and the 3-12 month age group followed by S. agalactiae and H. influenzae.

\section{Use of appearance and microscopy of CSF specimens to diagnose meningitis}

The appearance of CSF is considered in bacterial meningitis diagnosis but does not provide a definitive diagnosis [16]. In this study 6/53 CSF specimens from the confirmed cases of bacterial meningitis were cloudy. The 24 specimens which were clear and colorless were also positive for bacterial meningitis. The use of the appearance to indicate infection could be misleading, stressing the need to use additional laboratory diagnostic methods. It is generally accepted that patients with bacterial meningitis have a WBC count higher than 1,000 per $\mathrm{mm}^{3}$ while $99 \%$ have more than 100 per $\mathrm{mm}^{3}$. Having less than 100 WBCs per $\mathrm{mm}^{3}$ is more common in patients with viral meningitis [17]. However although a low WBC count in the CSF is consistent with viral infection, a bacterial aetiology cannot be ruled out because bacterial meningitis cases have been described without significant CSF WBC [18]. Fifty samples of the CSF specimens tested in this study had a WBC count of less than 5 and of those 13 cases were confirmed bacterial meningitis cases. The low WBC count may be attributed to HIV infection but HIV status was not established in the study. Ten of the 13 cases were on antibiotics although it is not possible to attribute failure to isolate bacteria to the treatment due to the small numbers involved. A greater percentage (82\%) of the CSF with a WBC $\geq 100 / \mathrm{mm}^{3}$ were confirmed as bacterial meningitis cases which is consistent with the standard description of a suspected bacterial infection and therefore a useful characteristic to assess the presence of bacterial meningitis where culture facilities are not available

Gram stain is regarded as a useful technique in resource limited settings although the sensitivity varies depending on the organism causing infection [10] and in this study detected $45 \%$ of the positive CSF samples. However out of the 29 CSF specimens in which S. pneumoniae was detected by PCR, 12 (41\%) were missed by Gram staining. Both Gram stain yields and culture may be decreased in antibiotic pretreatment [19]. This might be expected in Zimbabwe where empirical treatment of infection is high partly because of limited microbiology diagnostic support. However in this study the available data was not adequate to show a significant difference on Gram positivity between those who had pre-antibiotic treatment and those who did not. Of the 22 specimens which were positive on Gram stain, 4 were positive for patients who used antibiotic treatment before lumbar puncture while 6 were positive in those who did not use antibiotics before lumbar puncture while the remaining 12 had no data on pre-antibiotic use.

\section{Comparison of culture, serology and PCR to detect meningitis}

CSF culture is available in microbiology diagnostic laboratories in Zimbabwe. Routine application of quality assurance to the transport of CSF to the laboratory and to culture in this study increased the culture yield over the routine system from $0.5 \%$ (3546 specimens processed in 2010 and 2011) to $10 \%$. This increase in culture sensitivity could be attributed to use of sheep blood rather than the human blood normally used because of availability and cost to prepare blood agar and chocolate agar. As colony morphology and haemolysis are critical to the identification of meningeal bacterial organisms cultured on human blood can be overlooked or misidentified [20]. In addition ensuring that culture was performed within one hour of CSF collection, which although recommended is not always adhered to as $N$. meningitidis, $S$. pneumoniae, and $H$. influenzae are fastidious and fragile bacteria. Low detection rates compared to the non-culture methods could be due to low concentration of pathogens, small sample volumes or empirical antibiotic treatment prior to sample collection which can reduce 
Citation: Gudza-Mugabe M, Robertson V, Mapingure MP, Mtapuri-Zinyowera S, Mavenyengwa RT (2015) Prevalence of Salmonellosis among Food Handlers and the Health Implications on the Food Consumers in Lagos State, Nigeria. J Med Microb Diagn 4: 183. doi:10.4172/21610703.1000183

Page 5 of 6

sensitivity by up to $30 \%$ [16]. In this study there were 7 culture positive cases from the 27 participants (26\%) who used antibiotics compared to 14 cultures positive out of the 39 (36\%) cases who did not use antibiotics suggesting antibiotic use could play a role.

The use of the latex test and PCR significantly increased the detection rate. Of the 49 cases of bacterial meningitis diagnosed by the 3 methods: culture was positive for $17(35 \%)$, PCR detected 37 (76\%) and the latex test detected 36(74\%) cases. Out of the 152 culture negative CSF samples LA was positive in 19(13\%) while PCR was positive in $21(14 \%)$. Although the increased sensitivity was less than that found by Azzari et al., [11] with 5 to 10 times more cases detected by PCR than culture, in this study using LA and PCR twice as many cases were detected than by culture and confirming the bacterial nature of the infection with improved identification of specific pathogens.

Detection levels for S. pneumoniae between culture and PCR were significantly different $(\mathrm{p}=0.024)$ and more cases of $H$. influenzae were detected by PCR than either culture or LA. Increased numbers of S.agalactiae were detected by LA and the single case of $N$. meningitidis infection was only detected by LA and PCR. Both the increased detection rate and the wider range of pathogens detected using PCR in this and in other studies [13,21-23] suggest the importance of including PCR in the range of diagnostic tests available for the diagnosis of meningitis as a single test does not provide sufficient sensitivity, Latex agglutination detected 3 samples which were negative by PCR: S. pneumoniae (2) and $N$. meningitides (1) while PCR was positive with 16 samples which were negative with LA. It is possible that the concentration of organisms in these samples were tool low as the LA method requires the presence of $\geq 10^{3} \mathrm{CFU}$ of organisms per $\mathrm{ml}$ for optimal sensitivity [24]. It has been suggested that the diagnostic accuracy of LA is limited since false positive results are common [10].

Four specimens which were identified using LA as $S$. agalactiae were processed with PCR and 3 different organisms S. pneumonia (1), $N$. meningitides (1) and $H$. influenzae (2), were detected. The reason might have been due to dual infection or the latex agglutination being non-specific. Non-specificity of immunological testing results in crossreactivity. A previous study by Fischer et al., [25] discovered that the polysaccharide antigen in the polyvalent pneumococcal vaccine reacted to form precipitation lines with antisera directed against type14 pneumococcus and group-B streptococcus type III. The observed cross reactivity in the test for $S$. agalactiae with $N$. meningitidis and $H$. influenzae could have resulted in some false positives results. The non-specificity of the meningitis kit used (Pastorex Meningitis; Bio-Rad Laboratories) has been reported previously [26].

\section{Conclusion}

There was a significant difference in the results obtained from detection of meningitis causing organisms using culture, LA and PCR. The results confirmed that coupling of culture and non-culture methods improve performance in detecting the meningitis causing organisms. The routine dual use of LA and PCR is appropriate to improve meningitis case detection. Although LA, detected bacteria in less samples than PCR, it remains affordable and provides results in less than 15 minutes offering an advantage for early initiation of antibiotic treatment. Streptococcus agalactiae is increasingly becoming a cause of neonatal meningitis. Although PCR was not used in this study it is recommended to use the technique as its comparatively high sensitivity would lead to detection of many cases.

\section{Acknowledgements}

This work was made possible thanks to Harare Central Hospital Clinical Laboratory and National Microbiology Reference Laboratory staff. Special thanks to Linda de Gouveia of the National Institute of Communicable Diseases (NICD) South Africa. The contribution of the Ministry of Health and Child Care officials, WHO country office and Southern Africa Consortium for Research Excellence (SACORE) which provided financial support is acknowledged. We also thank $\mathrm{Dr} S$ Chimhuya for his contribution in facilitating sample collection.

\section{References}

1. Landrum LM, Hawkins A Goodman JR (2009) Pneumococcal meningitis during pregnancy: a case report and review of literature. Infect Dis Obstet Gynecol 63624.

2. Tzanakaki G, Tsopanomichalou M, Kesanopoulos K, Matzourani R, Sioumala $\mathrm{M}$, et al. (2005) Simultaneous single-tube PCR assay for the detection of Neisseria meningitidis, Haemophilus influenzae type b and Streptococcus pneumoniae. Clin Microbiol Infect 11: 386-390.

3. Gray KJ, Bennett SL, French N, Phiri AJ, Graham SM (2007) Invasive group B streptococcal infection in infants, Malawi. Emerg Infect Dis 13: 223-229.

4. WHO (2009) The Pediatric Bacterial Meningitis Surveillance in WHO S African Region.

5. MRF.Meningitis in Africa. 2011.

6. WHO (2006) Hib-Paediatric Bacterial Meningitis (Hib-PBM) Surveillance Network, Surveillance Manual.

7. [No authors listed] (2007) Pneumococcal conjugate vaccine for childhood immunization--WHO position paper. Wkly Epidemiol Rec 82: 93-104.

8. http://journals.Iww.com/nursing/Citation/2006/01000/Haemophilus influenzae_Type_B_Hib_.27.aspx

9. Close RM, Ejidokun OO, Verlander NQ, Fraser G, Meltzer M, et al. (2011) Early diagnosis model for meningitis supports public health decision making. $\mathrm{J}$ Infect 63: $32-38$.

10. Brouwer MC, Tunkel AR, van de Beek D (2010) Epidemiology, diagnosis, and antimicrobial treatment of acute bacterial meningitis. Clin Microbiol Rev 23 467-492.

11. Azzari C, Moriondo M, Indolfi G, Massai C, Becciolini L, et al. (2008) Molecular detection methods and serotyping performed directly on clinical samples improve diagnostic sensitivityand reveal increased incidence of invasive disease by Streptococcus pneumoniae in Italian children. J Med Microbiol 57 1205-1212.

12. Bronska E, Kalmusova J, Dzupova O, Maresova V, Kriz P, et al. (2006) Dynamics of PCR-based diagnosis in patients with invasive meningococcal disease. Clin Microbiol Infect 12: 137-141.

13. Kennedy WA, Chang SJ, Purdy K, Le T, Kilgore PE, et al. (2007) Incidence of bacterial meningitis in Asia using enhanced CSF testing: polymerase chain reaction, latex agglutination and culture. Epidemiol Infect 135: 1217-1226.

14. Mtapuri-Zinyowera LZ, Nathoo KJ, Chimhuya S, Jacha V, Gumbo P, et al. (2011) Laboratory training manual: paediatric bacterial meningitis. MoHCWNMRL, Zimbabwe.

15. Carvalho Mda G, Tondella ML, McCaustland K, Weidlich L, McGee L, et al (2007) Evaluation and improvement of real-time PCR assays targeting lytA ply, and psaA genes for detection of pneumococcal DNA. J Clin Microbiol 45 2460-2466.

16. Roca A, Bassat Q, Morais L, Machevo S, Sigauque B, et al. (2009) Surveillance of acute bacterial meningitis among children admitted to a district hospital in rural Mozambique. Clin Infect Dis 48: S172-180.

17. Seehusen DA, Reeves MM, Fomin DA (2003) Cerebrospinal fluid analysis. Am Fam Physician 68: 1103-1108.

18. [No authors listed] (1998) Viral meningitis. Paediatr Child Health 3: 433-436

19. Kanegaye JT, Soliemanzadeh P, Bradley JS (2001) Lumbar puncture in pediatric bacterial meningitis: defining the time interval for recovery of cerebrospinal fluid pathogens after parenteral antibiotic pretreatment. Pediatrics 108: 1169-1174.

20. Russell FM, Biribo SS, Selvaraj G, Oppedisano F, Warren S, et al. (2006)As a bacteria culture medium, citrated sheep blood agar is a practical alternative to citrated human blood agar in laboratories of developing countries. J Clin Microbiol 44: 3346-3351. 
Citation: Gudza-Mugabe M, Robertson V, Mapingure MP, Mtapuri-Zinyowera S, Mavenyengwa RT (2015) Prevalence of Salmonellosis among Food Handlers and the Health Implications on the Food Consumers in Lagos State, Nigeria. J Med Microb Diagn 4: 183. doi:10.4172/21610703.1000183

21. Virolainen A, Salo P, Jero J, Karma P, Eskola J, et al. (1994) Comparison of PCR assay with bacterial culture for detecting Streptococcus pneumoniae in middle ear fluid of children with acute otitis media. J Clin Microbiol 32: 26672670.

22. Nathan N, Rose AM, Legros D, Tiendrebeogo SR, Bachy C, et al. (2007) Meningitis serogroup W135 outbreak, Burkina Faso, 2002. Emerg Infect Dis 13: 920-923

23. Parent du Chatelet I, Traore Y, Gessner BD, Antignac A, Naccro B (2005) Bacterial meningitis in Burkina Faso: surveillance using field-based polymerase chain reaction testing. Clin Infect Dis 40: 17-25.
24. Cherian T, Lalitha MK, Manoharan A, Thomas K, Yolken RH, et al. (1998) PCREnzyme immunoassay for detection of Streptococcus pneumoniae DNA in cerebrospinal fluid samples from patients with culture-negative meningitis. $J$ Clin Microbiol 36: 3605-3608.

25. Fischer GW, Lowell GH, Crumrine MH, Wilson SR (1979) Immunoprecipitation and opsonic cross-reaction between type-14 pneumococcus and group-B streptococcus type III. Lancet 1: 75-77.

26. Ozaki T, Nishimura N, Arakawa Y, Suzuki M, Narita A, et al. (2009) Communityacquired Acinetobacter baumannii meningitis in a previously healthy 14 -monthold boy. J Infect Chemother 15: 322-324. 